\title{
Importance of the duration of nephropathy prior to tonsillectomy and steroid pulse therapy in IgA nephropathy patients
}

\author{
Norio Ieiri $\cdot$ Hotta Osamu
}

Received: 11 September 2014/ Accepted: 8 October 2014/Published online: 2 November 2014

(C) Japanese Society of Nephrology 2014

Keywords $\operatorname{IgA}$ nephropathy $\cdot$ Duration of nephropathy · Tonsillectomy and steroid pulse therapy $\cdot$ Clinical remission $\cdot$ Lead time bias $\cdot$ Annual urinalysis screening system

\section{To the Editor,}

Suzuki et al. [1] showed in their original article that the number of years from diagnosis until tonsillectomy and steroid pulse (TSP) therapy did not influence the clinical remission (CR) rate in $\operatorname{IgA}$ nephropathy (IgAN) patients treated with TSP, and they concluded that their results were not in accordance with our previous study [2] which demonstrated that a shorter duration from diagnosis until TSP was associated with a high likelihood of CR in IgAN patients treated with TSP.

Our previous study [2] demonstrated that the duration of nephropathy (DN), not the number of years from diagnosis until TSP therapy, was the most veridical predictor of CR as compared with other clinical features such as estimated glomerular filtration rate, age or degree of proteinuria at time of initiation of treatment in IgAN patients treated by TSP therapy. In our study the DN was defined as the period from the first manifestation of hematuria to the initiation of TSP therapy. As the annual urinalysis screening system in Japan is well established, such checkups enable the DN to be accurately estimated. In fact, the onset year of nephropathy could be identified in $59.6 \%(495 / 830)$ of IgAN patients in our study.
In discussion the DN, we think the number of years from diagnosis until TSP therapy seems to be not reliable, because such duration was influenced by the policy of the indication of renal biopsy in each hospital and also by the differing frequencies of medical checkups among patients, resulting in a considerable lead time bias [3] in each patient.

Thus, we think the conflicting results between Suzuki K et al. and ours are ascribed to the difference in the definition of the "duration" prior to TSP therapy.

Conflict of interest The authors have declared that no conflict of interest exists.

\section{References}

1. Suzuki K, Miura N, Imai H. Estimated glomerular filtration rate and daily amount of urinary protein predict the clinical remission rate of tonsillectomy plus steroid pulse therapy for IgA nephropathy. Clin Exp Nephrol. 2014;18:606-12.

2. Ieiri N, Hotta O, Sato T, Taguma Y. Significance of the duration of nephropathy for achieving clinical remission in patients with $\operatorname{IgA}$ nephropathy treated by tonsillectomy and steroid pulse therapy. Clin Exp Nephrol. 2012;16:122-9.

3. Geddes CC, Rauta V, Gronhagen-Riska C, Bartosik LP, Jardine AG, Ibels LS, et al. A tricontinental view of IgA nephropathy. Nephrol Dial Transplant. 2003;18:1541-8. 